\title{
Tratamiento restaurador atraumático con gel removedor de lesiones cariosas
}

Atraumatic restorative treatment with carious lesion remover gel
Tratamento restaurador atraumático com gel

de remoção de lesão carosa
Fecha de Recepción

10 de abril de 2016
Aceptado para su publicación

18 de diciembre de 2016
Horacio Romero

Jefe de Trabajos Prácticos. Hospital Odontológico

Universitario. FOUNNE

Fernando Andrés Velozo

Jefe de Trabajos Prácticos. Hospital Odontológico

Universitario. FOUNNE

María Cristina Ojeda Jefe de Servicio de Atención Odontológica para Personas con Capacidades Diferentes.

FOUNNE

Lugar de Trabajo

Facultad de Odontología.

Avda Libertad 5450. Tel./fax: 3783-57992

Código postal: 3400

\section{Resumen}

En la década del 80 , surge una nueva técnica en la práctica odontológica con la finalidad de atender poblaciones de alto riesgo social y biológico. Estos tratamientos consisten en preservar la mayor cantidad de tejido dental, eliminando, con instrumental de mano, dentina necrótica e infectada, respetando la que puede ser remineralizada con materiales dentales adhesivos con liberación de fluoruros.

Los avances de la ciencia odontológica, ofrece en la actualidad, la alternativa de utilizar detectores químicos, con propiedades bactericidas, bacteriostáticas, y antiinflamatorias.

Se presenta el caso de un niño de 10 años, con retraso mental moderado, con caries amelodentinaria, a la cual se le realizó tratamiento con BRIX 3000, .producto odontológico en gel para el tratamiento atraumático de caries, cuyo componente es la papaína, con una actividad enzimática de $3000 \mathrm{U} / \mathrm{mg}$. (unidades internacionales de medición de la actividad enzimática específica o la concentración de actividad enzimática)'

\section{Palabras Claves}

Caries, Tratamiento Restaurador Atraumático, Gel Enzimático.

\section{Summary}

In the decade of the 80 , a new technique in the dental practice arises with the purpose of 
attending populations of high social and biological risk. These treatments consist of preserving the largest amount of dental tissue, eliminating, with hand instruments, necrotic and infected dentin, respecting the one that can be remineralized with adhesive dental materials with fluoride release.

The advances of dental science, currently offers the alternative of using chemical detectors, with bactericidal, bacteriostatic, and antiinflammatory properties.

We present the case of a 10-year-old boy with moderate mental retardation with amelodentinous decay, who was treated with BRIX 3000 , a dental gel product for the atraumatic treatment of decay, the component of which is papain, with An enzymatic activity of $3000 \mathrm{U} /$ $\mathrm{mg}$. (International units of measurement of specific enzyme activity or concentration of enzyme activity)'.

\section{Key words}

Decay, Atraumatic Restorative Treatment, Enzymatic Gel.

\section{Resumo}

Nos anos 80 , surgiu uma nova técnica na prática odontológica, a fim de servir populações com alto risco social e biológica. Estes tratamentos consistem preservar tanto do tecido dental, eliminando, com instrumentos manuais, dentina necrótica e infectados, respeitando pode ser remineralizada com materiais adesivos dentários com libertação de fluoreto.

Os avanços na ciência dental, oferece actualmente a alternativa de utilizar detectores químicos, com bactericida, bacteriostática e antiinflamatória.

Para um rapaz de 10 anos apresentada com atraso mental moderado, com cavidades amelodentinal, a que foram submetidos a tratamento com BRIX 3000, gel de .producto dental para tratamento atraumática de cárie, o componente que é a papaína, com uma actividade enzimática de $3000 \mathrm{U} / \mathrm{mg}$. (unidades internacionais de medição de actividade ou concentração de actividade enzimática específica da enzima) $)^{1 .}$

\section{Palavras chave}

Cárie, Atraumatic Tratamento Restaurador, Gel enzimática.

\section{Introducción}

En la clínica odontológica se deben resolver diferentes dificultades, algunas, relacionados al paciente, otras al operador y a veces, al caso clínico propiamente dicho. Las soluciones se presentan con distintas alternativas de tratamiento, sobre todo, ante las enfermedades de mayor prevalencia, como son las caries dentales y las enfermedades gingivo-periodontales.

La caries dental es una afección que provoca la mayor morbilidad dentaria durante toda la vida de una persona, independientemente de la edad, sexo y raza, pero con mayor prevalencia en grupos poblacionales de bajo nivel socioeconómico, situación que guarda relación directa con bajo nivel educativo, mayor frecuencia en el consumo de alimentos ricos en sacarosa entre las comidas y ausencia de hábitos higiénicos.

Los nuevos abordajes de diagnóstico con criterios conservadores, replantean la necesidad de actualizar los tratamientos restauradores y preventivos a las nuevas tecnologías disponibles. En la actualidad, clasificaciones diagnósticas valoran, no solo la extensión y profundidad de la lesión, sino también su pronóstico restaurador basado en el desarrollo de tecnologías y materiales adhesivos. Esto convierte al diagnóstico integral de la caries dental en un paso determinante para la elección del tratamiento adecuado.

El procedimiento denominado Tratamiento Restaurador Atraumático (ART) se basa en eliminar las caries dentinarias utilizando únicamente instrumental manual, y su posterior obturación con materiales adhesivos.

La técnica ART, se complementa con la utilización de una enzima proteolítica, bactericida, antiinflamatoria, que elimina únicamente el tejido cariado irreversible sin acción sobre la dentina sana. Entre sus ventajas podemos resaltar que posee buen tiempo de permanencia en boca, sin necesidad de aislamiento absoluto, demuestra una alta conservación de material biológico con respecto a la técnica convencional, no presenta reacciones inflamatorias en los tejidos adyacentes al tratamiento, no produce residuos volátiles 
REVISTA FACULTAD DE ODONTOLOGÍA

ISSN No 1668-7280 - Vol. X No 1 - 2017

40

CASO CLINICO

Romero - Velozo - Ojeda y presenta una alta aceptación por parte del paciente.

El gel de papaína removedor de caries Brix 3000 , actúa sobre las fibras de colágeno degradadas por la acción de la caries y sobre las células muertas. Adicionalmente, contiene un colorante, azul de toluidina el cual actúa como un potente agente antimicrobiano

Es una técnica sencilla que se puede utilizar en niños, en pacientes aprensivos, como así también en personas con discapacidad, con excelentes resultados.

\section{Caso Clínico}

Se realizó en un paciente de 10 años de edad, con retraso mental moderado, quien presenta lesión de caries en la pieza dentaria $\mathrm{N}^{\circ}$ 63.- canino temporario superior derecho, observándose clínicamente caries amelodentinaria de color marrón de consistencia blanda, en la superficie mesial. Figura $\mathrm{N}^{\circ}$ I.

Se procedió al protocolo, remoción químicomecánico, siguiendo la secuencia de colocación del gel removedor enzimático Brix 3000 en 2 momentos de 2 minutos cada uno, con lavados intermedios entre ambos. Figura $\mathrm{N}^{\circ} 2$

Luego de observar la correcta eliminación del tejido desmineralizado, se utilizó para terminar la remoción de los residuos de caries, instrumental manual con leve presión. Lavado antiséptico con digluconato de clorhexidina, para posteriormente realizar la obturación con lonómero vítreo. Figura $\mathrm{N}^{\circ} 3$

El tiempo promedio de trabajo no superó los siete minutos.

\section{Discusión}

Estudios realizados sobre la aplicación del gel BRIX 3000, demostró alta efectividad en su primera aplicación, (negativos 90\%); posee un tiempo promedio de trabajo clínico en boca de 7,5 minutos, buen tiempo de permanencia en boca sin aislamiento absoluto $y$ antes de sufrir desecamiento, la diferencia en tamaño cavitario pre y post operatoria demuestra un alta conservación de material biológico con respecto a la técnica convencional ( Bsereni L 2005).
Asimismo, el éxito y beneficios encontrados amplían sus indicaciones iniciales y se utiliza actualmente en otros pacientes, ancianos, personas con dificultad para el cepillado, como así también las que se encuentran en zonas o poblaciones que carecen de suministros de agua $y$ electricidad. (Aldana, C. 2005)

Investigaciones recientes, en niños de 3 a 5 años, constató una diferencia estadísticamente significativa $(p<0.00)$ en relación al tiempo empleado en los dos tratamientos propuestos ART convencional y ART modificado por el sistema de remoción químico-mecánico, fue más rápido en relación al tiempo de trabajo, en la eliminación de la caries dental, en escolares de 3 a 5 años de edad, frente al ART (Tratamiento restaurador atraumático) convencional. (Collaguazo 2015) Las personas con necesidades especiales en salud requieren de una serie de atenciones específicas según el tipo de patología que presenten, por lo tanto, la práctica odontológica requiere de una serie de cuidados adicionales para una atención segura y de calidad. (Vergara Silva, D.2013)

Para estos casos, el tratamiento restaurador atraumático, complementado con productos químicos, como el gel de papaína, reduciría considerablemente el tiempo de trabajo clínico y por ende, mayor control de la ansiedad del paciente y del operador.

\section{Conclusiones}

La utilización del gel para remover lesiones de caries Brix 3000 es efectivo y selectivo en su acción proteolítica para remover fibras de colágeno degradadas de la dentina infectada, dando como resultado preparaciones conservadoras con economía de tejidos, por requerir mínima preparación de la cavidad. Al ser una técnica indolora, evita la aplicación de anestesia, y el empleo de instrumental rotatorio.

Debido a su naturaleza mínimamente invasiva, es adecuada para niños, adultos temerosos, personas con discapacidad, pacientes hospitalizados, personas ancianas, y de gran utilidad en actividades de extensión. El éxito del tratamiento dependerá del respeto a la secuencia del protocolo y el complemento de métodos preventivos y de Educación para la Salud. 
REVISTA FACULTAD DE ODONTOLOGÍA

ISSN No 1668-7280 - Vol. X No 1 - 2017

41
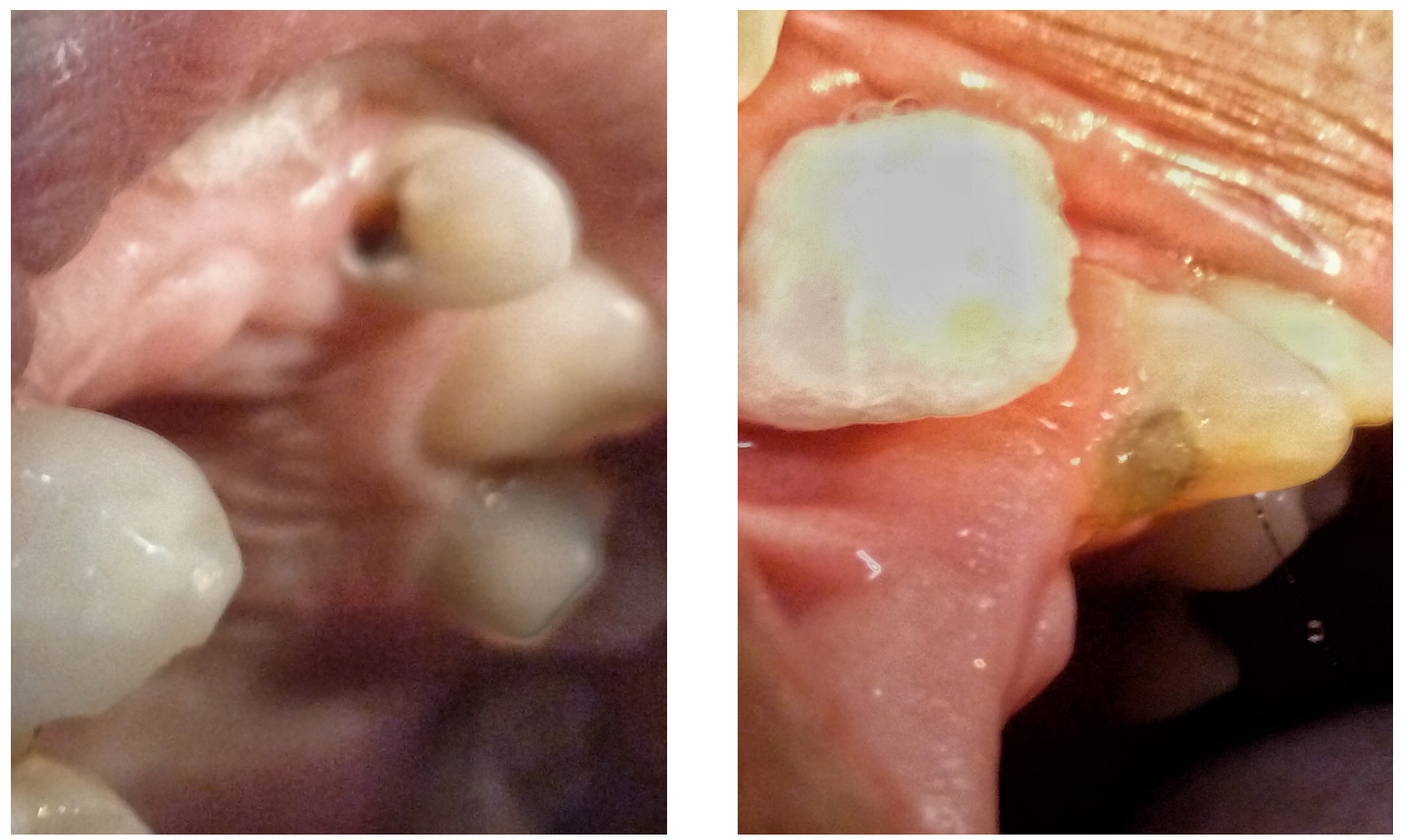

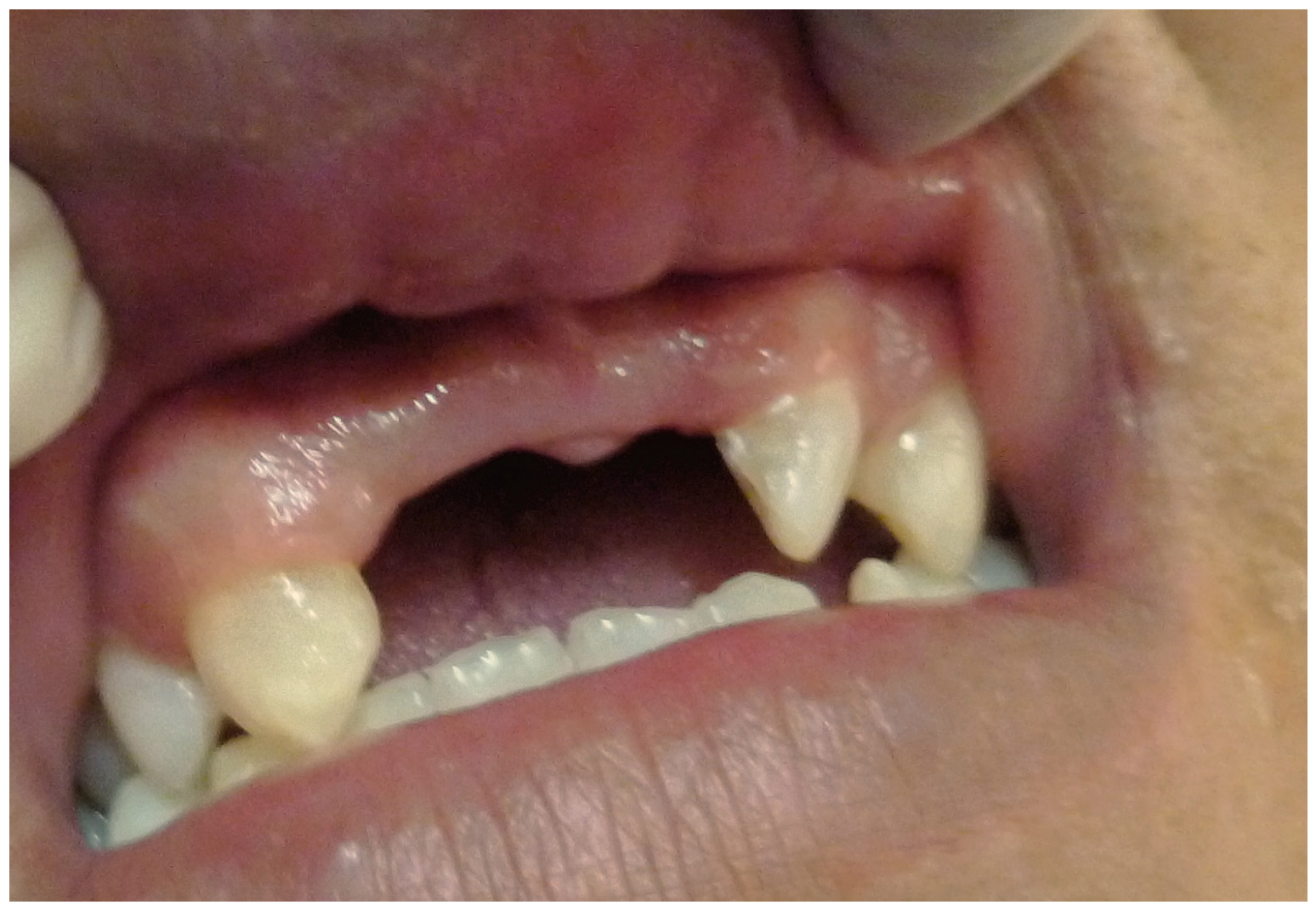




\section{Bibliografía}

I. BRIX 3000. Disponible: www.brix-lab.com/index.php/es/brix3000 Acceso 05/04/2017

2. Cueto Rostom V. Diagnóstico y tratamiento de lesiones cariosas incipientes en caras oclusales. Odontoestomatología 2009; II (I3): 4-I5

3. Alfaro, M. R., Lazo, S. D., Pazos, F., Di Salvi, N., Alfaro, G. E., \& Escudero Giachella, ECon capacidad para la discapacidad. In Proyecto de la Secretaría de Extensión de la Facultad de Odontología (UNLP). 2016.

4. Collaguazo, C., \& Elizabeth, P. Comparación de dos técnicas atraumáticas para la eliminación de caries dental en niños de 3 a 5 años de edad de la Fundación" Odd Hansen" de la ciudad de Machachi (Bachelor's thesis, Quito: Universidad de las Américas, 20I5).

5. Mateos Palacios, R. Uso de medios químico-mecánicos como apoyo en el tratamiento restaurador atraumático en personas mayores: ensayo clínico aleatorizado, doble ciego, en caries radiculares. Universidad de Granada. $20 \mid 4$.

6. Flores Romero, J., García León, E., Gutiérrez Cornejo D., Álvarez Páucar, M. A. Técnica de Restauración Atraumática. Facultad de Odontología. Universidad Mayor de San Marcos.Lima. Perú. 2010: 24.

7. Edelberg MHAdhesión en odontología restauradora. Adhesión con ionómeros vítreos. Editorial MAIO. Brasil. 20036 (I37-162).

8. Frencken JE, Holmgren CJ. Atraumatic Restorative Treatment for dental caries. Nijmegen: STI book; 1999: p 99.
9. Lanata Eduardo, Operatoria Dental: Estetica y Adhesión Operatoria dental. - 2a. ed. - Buenos Aires : Alfaomega Grupo Editor Argentino, 201 I.

10. A. Lussi, R. Hibst and R. Paulus. DIAGNOdent: An Optical Method for Caries Detection. J Dent Res 2004; 83 (Spec Iss C): C80-C83.

II. Fusayama t International Dental Journal Volume 47, Issue 3, pages I57-166, June 1997.

12. Massara M, Alves J, Brandao P. Atraumatic restorative treatment: clinical, ultrastructural and chemical analysis. Caries Res. 2002; 36: 430-6.

13. Lo ECM, Holmgren CJ. Provision of atraumatic restorative treatment (ART) restorationsto Chinese pre-school children: a 30-month evaluation. Int J Paed Dent. 200 I; I I: 3-10.

14. Silva, L. R., Tonolli, G., Santos, E. M., Bussadori, S. K. Avaliação da biocompatibilidade "in vitro" de um novo biomaterial para a remoção química e mecânica da cárie. In: $20^{\mathrm{a}}$ Reunião Anual SBPqO, 2003, Águas de Lindóia. 2003. Anais. Pesquisa Odontológica Brasileira. v. 17. p.93. Acceso 03/05/2014.

15. Vergara Silva, D. B. Comparación del tiempo requerido para la atención odontológica de pacientes con epidermolisis bullosa y pacientes sanos. Repositorio.uchile.cl 2013 Acceso 07/06/2014.

16. Aldana, C. O., \& de Priego, G. P. M. (2005). Técnica restaurativa atraumática. Conceptos actuales. Revista Estomatológica Herediana, 15 (I), 77-8I. Acceso 25/04/20I4.

17. Bsereni, L., \& Torresi, F. V. Estudio de la eficacia del gel de PapaínaBrix3000. Acceso 01/07/2017. 